\title{
Pre-impact fall detection using an inertial sensor unit
}

\author{
Soonjae Ahn, Isu Shin, Youngho Kim* \\ From 4th Congress of the International Foot and Ankle Biomechanics (i-FAB) Community \\ Busan, Korea. 8-11 April 2014
}

Falls are a major cause of injuries and deaths in older adults [1]. As for intervention strategies, one of the important problems in preventing or reducing the severity of injury in the elderly is to detect falls in its descending phase before the impact [2]. If a fall can be detected in its earliest stage in the descending phase, more efficient impact reduction systems can be implemented with a longer lead-time for minimizing injury $[3,4]$. In this study, we implemented a pre-impact fall detection algorithm using an inertial sensor unit.

Totally, forty male volunteers participated in the experiment (three types of falls and seven types of ADLs). An inertia sensor unit, placed at waist, was used to measure subject's acceleration, angular velocity and vertical angle during various activities. In order to detect pre-impact, the threshold of acceleration and angular velocity was set to $0.8 \mathrm{~g}$ and $30^{\circ} \mathrm{s}$, respectively, based on the data from the first twenty subjects. Furthermore, the threshold of vertical angle was set to $30^{\circ}$ because the maximum angle in the
ADL did not exceed $30^{\circ}$. This fall detection algorithm was evaluated for another twenty subjects.

The results showed that both acceleration and angular velocity during three different falls were greater than the threshold during several ADLs and the vertical angle did not exceed $30^{\circ}$. The vertical angle exceeded $30^{\circ}$ only during sit-lying activity, but the acceleration did not reach $0.8 \mathrm{~g}$ (Table 1). Based on the pre-impact fall detection algorithm, no false detection was found $(100 \%$ sensitivity) for all falls.

Furthermore, no incorrect detection was found (100\% specificity) for all ADLs. The lead time was $474 \pm$ $38.3 \mathrm{~ms}, 590.3 \pm 122.6 \mathrm{~ms}$ and $527 \pm 62.3 \mathrm{~ms}$ in the backward, the forward and the side falls, respectively.

In this study, a pre-impact fall detection algorithm was developed using an inertial sensor unit. The present preimpact fall detection algorithm can be implemented with a wearable fall injury minimization system to track a user's body movement.

Table 1 Peak acceleration, angular velocity and vertical angle during falls and ADLs.

\begin{tabular}{|c|c|c|c|c|c|c|}
\hline \multicolumn{2}{|c|}{ Trials } & \multirow[t]{2}{*}{ Acceleration (g) } & \multicolumn{2}{|c|}{ Angular velocity $(\% / s)$} & \multicolumn{2}{|c|}{ Angle $\left({ }^{\circ}\right)$} \\
\hline & & & Pitch & Roll & Sagittal & Lateral \\
\hline \multirow[t]{3}{*}{ Falls } & Backward & $4.1 \pm 0.6$ & $300.3 \pm 59.7$ & $45.7 \pm 14.2$ & $94.2 \pm 4.7$ & $4.7 \pm 3.2$ \\
\hline & Forward & $4.5 \pm 0.5$ & $220.6 \pm 41.6$ & $75.9 \pm 17.2$ & $89.6 \pm 9.2$ & $8.4 \pm 4.6$ \\
\hline & Side & $4.4 \pm 0.6$ & $121.2 \pm 13.7$ & $419.4 \pm 61.3$ & $6.69 \pm 2.7$ & $75.95 \pm 12.4$ \\
\hline \multirow[t]{6}{*}{ ADLs } & Sit-Stand & $1.4 \pm 0.2$ & $110 \pm 23.1$ & $8.9 \pm 7.6$ & $31.1 \pm 6.1$ & $2.6 \pm 1.3$ \\
\hline & Stand-Sit & $2.2 \pm 0.3$ & $392.3 \pm 61.3$ & $11.2 \pm 6.1$ & $11.63 \pm 3.1$ & $1.12 \pm 2.7$ \\
\hline & Sit-Lying & $1.1 \pm 0.1$ & $80.7 \pm 31.7$ & $15.3 \pm 3.8$ & $90.3 \pm 8.3$ & $4.3 \pm 2.8$ \\
\hline & Walking & $2.1 \pm 0.2$ & $50.1 \pm 10.9$ & $59.3 \pm 14.9$ & $1.4 \pm 6.2$ & $2.1 \pm 3.1$ \\
\hline & Jump & $7.5 \pm 1.1$ & $421.2 \pm 149.1$ & $102.3 \pm 62.1$ & $27.3 \pm 2.1$ & $3.6 \pm 3.8$ \\
\hline & Running & $4.2 \pm 0.9$ & $132.8 \pm 45.7$ & $98.2 \pm 34.9$ & $11.5 \pm 9.7$ & $2.6 \pm 4.1$ \\
\hline
\end{tabular}

\footnotetext{
* Correspondence: younghokim@yonsei.ac.kr

Department of Biomedical Engineering and Institute of Medical Engineering, Yonsei University, Wonju, Gangwon, 220-710, Korea
} 


\section{Acknowledgement}

This research was supported by the Human Resource Training Project for Regional Innovation through the National Research Foundation of Korea (NRF) funded by the Ministry of Education (2013H1B8A2032194).

Published: 8 April 2014

\section{References}

1. Annekenny R, O'Shea D: Falls and syncope in elderly patients. Clinics in Geriatric Medicine 2002, 18:xiii-xiv.

2. Bourke AK, O'Donova KJ, O' Laighin G: The identification of vertical velocity profiles using an inertial sensor to investigate pre-impact detection of falls. Medical Engineering \& Physics 2008, 30:937-946.

3. Wu G: Distinguishing fall activities from normal activities by velocity characteristics. Journal of Biomechanics 2000, 33:1497-1500.

4. Nyan MN, Tay FE, Tan AW, Seah KH: Distinguishing fall activities from normal activities by angular rate characteristics and high-speed camera characterization. Medical Engineering \& Physics 2006, 28:842-849.

doi:10.1186/1757-1146-7-S1-A124

Cite this article as: Ahn et al.: Pre-impact fall detection using an inertial sensor unit. Journal of Foot and Ankle Research 2014 7(Suppl 1):A124.

\section{Submit your next manuscript to BioMed Central} and take full advantage of:

- Convenient online submission

- Thorough peer review

- No space constraints or color figure charges

- Immediate publication on acceptance

- Inclusion in PubMed, CAS, Scopus and Google Scholar

- Research which is freely available for redistribution

Submit your manuscript at www.biomedcentral.com/submit
(Ciomed Central 